\title{
Família no plural: o grande desafio das políticas sociais na contemporaneidade
}

\section{Família, gênero e gerações: desafios para as políticas sociais.}

BORGES, Ângela; CASTRO, Mary Garcia (Orgs.).

São Paulo: Paulinas, 2007.
Os cinco artigos que compõem o livro Família, gênero e gerações: desafios para as políticas sociais, em diferentes linhas de pensamento e com diferentes abordagens, trazem à reflexão questões extremamente importantes para pensarmos a sociedade contemporânea, em especial, as políticas públicas no Brasil. As discussões desse livro levam em consideração uma questão extremamente importante para as políticas públicas contemporâneas, a questão de que a instituição "família" não morreu, mas no lugar da família, tratada durante muito tempo no singular, ressaltam-se outros arranjos familiares, que fazem com que as famílias, na contemporaneidade, sejam tratadas exatamente assim, no plural.

Diante das inúmeras mudanças e transformações dos séculos XX e XXI, novos parâmetros nas relações de gênero e de gerações surgem e são cada vez mais fortificados, da mesma forma surgem e intensificam-se novos e variados arranjos familiares. Os estudos científicos sobre o tema família caminharam a passos lentos até efetivamente fazerem parte das abordagens acadêmicas no Brasil, da mesma forma caminham as políticas sociais voltadas para a família que não acompanham efetivamente as mudanças pelas quais estas vêm passando e, principalmente, não assistem de maneira eficiente os diferentes e variados arranjos familiares existentes na atualidade.

Nessa perspectiva, grande parte dos artigos do livro relata a importância de as perspectivas de gênero e gerações serem consideradas nos estudos sobre famílias contemporâneas, além de outras categorias sociais importantes, como classe e raça/etnia, que devem ser, nesse caso, entrelaçadas ou trabalhadas em uma perspectiva de interseccionalidade. Dessa forma, estudos e pesquisas voltados à pluralidade das famílias brasileiras podem influenciar o surgimento de novas políticas sociais, que permitam compreender mais claramente e atender mais efetivamente as famílias brasileiras na contemporaneidade.

O artigo de abertura do livro, escrito pelo sociólogo italiano Sergio Belardinelli, assume uma postura diferente dos demais textos publicados, pois não se baseia diretamente em dados de pesquisas científicas, estando muito mais próximo de um artigo de opinião. Belardinelli faz uma crítica aos autores Giddens e Beck, a partir do questionamento de conceitos como o de "relações puras" e o de "família pós-familiar". É dentro de uma perspectiva funcionalista, que percebe a família como uma instituição social com funções delimitadas, que Belardinelli defende o conceito de "família tradicional", formada por um casal heterossexual com filhos. Para o autor, apesar das variadas formas de união - frutos de uma sociedade liberal que favorece as individualidades -, apenas a família tradicional deve ser realmente considerada família e deve ser privilegiada pelo Estado Liberal, pois apenas ela pode assumir as funções sociais de reprodução e de sociabilidades das crianças, sendo assim um capital social valioso. Segundo Belardinelli, a predileção desse modelo familiar diante dos outros é a única forma de manter um Estado com valores pluralistas e respeitosos das liberdades individuais.

O artigo seguinte, de autoria das pesquisadoras Mary Garcia Castro, Marlene Barreto S. Miranda e Nadir Oliveira Galrão Leite de Almeida, dá início, efetivamente, ao que parece ser a ideia principal do livro, discutir, a partir de estudos e pesquisas acadêmicas, as relações familiares na atualidade, levando em consideração categorias sociais como gênero e gerações. Ao discutir, a partir de dados de pesquisas realizadas no Brasil na atualidade, os comportamentos e as percepções de jovens e seus pais diante da sexualidade juvenil, principalmente com relação a fatores como iniciação sexual, as autoras privilegiam as duas categorias citadas no título do livro. Os resultados 
das pesquisas trazem reflexões importantes principalmente no ponto de vista das relações de gênero, já que, segundo as autoras, na contemporaneidade tradição e modernidade andam lado a lado no que se refere à sexualidade, e mesmo uma orientação familiar considerada "moderna" suporta elementos "tradicionais", que pesam, ainda na atualidade, muito mais sobre o gênero feminino do que sobre o masculino. Com base nesses estudos, as autoras chegam à conclusão de que a sexualidade é um dos temas mais difíceis entre a família e os jovens, pois está no meio de confrontos geracionais e de gênero.

O terceiro artigo, escrito por Alda Britto da Motta, também aborda a categoria gênero e, principalmente, a categoria geração ao discutir as relações geracionais existentes na família contemporânea, abordando principalmente os/ as idosos/as. Partindo de uma ampla revisão de literatura sobre o tema, e de dados de pesquisas realizadas no Brasil, Motta dá ênfase, em seu trabalho, ao processo de envelhecimento e a cada vez mais crescente longevidade e suas implicações nas relações familiares e na vida social. Para a autora, surgem novas configurações nos ciclos de vida que ampliam as alternativas de vivências e que tornam as opções de arranjos familiares quase ilimitadas. Dentro dessa perspectiva, a autora ressalta a importância social dos idosos diante da manutenção de suas famílias, e nesse sentido enfatiza a posição das idosas, mulheres, que assumem em maior número a chefia da casa/família. Esse fato, segundo Motta, acontece devido à omissão e negligência do Estado e suas políticas públicas com relação à família e aos jovens. Em virtude dessa realidade, a autora ressalta a importância de uma regulação justa das aposentadorias no Brasil. Motta chama atenção para as diferenciações entre os idosos, que vão além das distinções de gênero, classe e raça/etnia. Utilizando-se do conceito de habitus, adotado por Bourdieu, a autora defende a existência de diferenciações geracionais entre os idosos.

No quarto capítulo, Márcia S. Macêdo, importante estudiosa sobre chefia familiar feminina no Brasil, traz algumas reflexões teóricas sobre esse campo de análise. A autora defende a categoria gênero como essencial para os estudos de família, porém, explicita sua vinculação a uma perspectiva relacional que pensa a vida social a partir da interação de categorias como gênero, classe, raça/etnia e idade/geração.

Todavia, a autora dá importância especial à categoria gênero em seu trabalho, colo- cando-a numa posição central para os estudos de família. Para ela, a perspectiva de gênero vai além das posições sociais exercidas por homens e mulheres, explica as relações sociais pautadas por essas diferenciações. Segundo ela, essa perspectiva possibilita o maior entendimento das diversidades familiares na contemporaneidade. Macêdo, dessa forma, dá maior atenção às famílias chefiadas por mulheres, que, para ela, não são uma "nova realidade", mas, por terem sido expandidas recentemente, em todos os níveis sociais, principalmente entre as camadas médias, vêm tendo ampla visibilidade. Mostra-se claro, porém, que esse arranjo acontece de maneira mais expressiva entre a população mais empobrecida e é fruto de inúmeros fatores sociais. Nessa perspectiva, a autora critica a ideia tão amplamente difundida de "feminização da pobreza", que, para ela, associa negativamente a chefia feminina e a pobreza. Essa perspectiva oferece uma análise simplificada e desconsidera importantes fatores das relações de gênero, como a desvantagem feminina com relação ao mercado de trabalho, além do ainda atual enfrentamento de barreiras culturais e da adoção de uma dupla jornada de trabalho pelas mulheres - nos âmbitos da produção e da reprodução. Para Macêdo, outros indicadores de bem-estar não são considerados por essa análise, já que a realidade mostra que a maior parte do rendimento das mulheres chefes de família é destinada à manutenção do lar.

Os dois últimos artigos versam em torno da discussão sobre a necessidade de implementação de políticas sociais e políticas públicas que atendam mais efetivamente as diversidades de arranjos familiares no Brasil contemporâneo.

O artigo de Ângela Borges, o quinto do livro, propõe-se a falar do que ela chama de "os impactos da reestruturação do capitalismo no final do século XX" sobre a sociedade brasileira, especialmente sobre os que vivem do trabalho. Para a autora, esses impactos repercutem em toda a vida social, inclusive nas famílias, que, entre outros fatores, devido a essa reestruturação, devem adaptar-se continuamente ao mercado de trabalho e às condições impostas por ele, o que ocasiona constantes rearranjos das formas familiares, principalmente em um país como o Brasil, onde, historicamente, segundo Borges, há uma grande fragilidade nas políticas de proteção social. A autora baseia-se em dados da Pesquisa Nacional por Amostra de Domicílios - PNAD, realizada na Região Metropolitana de Salvador. Segundo ela, 
fundamentando-se essencialmente nos dados coletados nessa região do país, as mudanças nas formas familiares tornam-se cada vez mais expressivas nesse processo de reestruturação do Estado, principalmente com o desemprego elevado dos homens e a entrada das mulheres no mercado de trabalho. Segundo a autora, o impacto da reestruturação produtiva pode ser amplamente percebido, além de outros fatores, ao interferir na capacidade de provisão e cuidados da família, essenciais para o bem-estar de seus membros. Para ela, um dos pilares para a provisão desses cuidados é o trabalho doméstico não remunerado, que é de grande importância, porém, socialmente desvalorizado. Esse trabalho, que é historicamente reconhecido como um papel feminino, ainda é exercido em maior parte pelas mulheres, apesar de sua entrada no mercado de trabalho, o que causa problemas em sua qualidade de vida. Para Borges, a mudança dessa situação tem que partir do Estado, já que as políticas sociais no Brasil são limitadas e baseadas na existência de um membro da família (mulher) que mantenha um trabalho de cuidado, não levando em consideração inúmeros fatores essenciais, como a participação cada vez maior das mulheres no mercado de trabalho.

O último texto, escrito por Giancarlo Petrini, dá continuação a discussões de outros artigos do livro, principalmente no que se refere às políticas sociais. Enfatiza as transformações sofridas pela família na contemporaneidade e sua diversidade de arranjos, fugindo de qualquer vínculo com modelos tradicionais. Para Petrini, as novas famílias têm uma disposição muito maior a convivências democráticas e igualitá- rias, tanto nas relações de gênero como geracionais, e as inovações tecnológicas deram outro sentido à sexualidade e, consequentemente, às famílias, visto que a maternidade tornou-se fator de escolha. Outras mudanças no campo cultural fizeram com que a família passasse a ser vista muito mais como uma relação entre diferentes indivíduos. Diante dessa perspectiva, a família assume um caráter de desinstitucionalização, porém, para Petrini, essas mudanças podem contribuir para "tornar fracas as redes da solidariedade familiar, mais frágeis os vínculos de pretensa recíproca [...] menos importantes as relações de parentesco" (p. 216). Assim, o que o autor chama de "polo da integração", existente nas famílias "tradicionais", é substituído nas formas familiares modernas pelo "polo da autoafirmação" e de uma cultura do individualismo. Para Petrini, no Brasil, tradicionalmente as políticas públicas são voltadas para os indivíduos e é necessário que se criem políticas de atendimento às famílias como um conjunto. Para o autor, a administração pública no Brasil preocupa-se com outros fatores, não com a família. E, apesar de algumas iniciativas serem voltadas para a família, elas não são vinculadas, não apresentam uma integração e deixam de surtir os efeitos necessários, sendo em sua maioria políticas emergenciais. Para ele, as famílias não são suficientemente compreendidas e, apesar das diversidades entre elas, é necessário encontrar um ponto em comum para o investimento em políticas que, para ele, fossem "políticas familiares".

Sara Simas

Universidade do Estado de Santa Catarina 